\title{
Revisiting Types and Risk Factors for Thyroid Malignancy in a State Endemic of lodine Deficiency Goiter
}

\author{
${ }^{1}$ Mei W Wong, ${ }^{2}$ Imisairi A Hadi, ${ }^{3}$ Kamarul I Musa
}

\section{ABSTRACT}

Introduction: We have realized that recent rise in incidence of thyroid malignancy is partly because of incidental findings of cancer after resection for benign goiters. Therefore, we aim to reanalyze risk factors for thyroid malignancy in those patients who underwent primary thyroid surgery at Breast and Endocrine Surgical Unit, Department of Surgery, Hospital Raja Perempuan Zainab II, Kota Bharu, Kelantan, Malaysia.

Materials and methods: Retrospective review in our database found 699 patients who had undergone thyroid surgeries between June 2007 and December 2014. According to the final histopathological report of resected specimen, these patients, operated for goiter, were divided into two groups: Thyroid malignancy group and nonmalignancy group. Logistic regression analysis was used to estimate the risk of age, duration and weight of resected specimen for having thyroid malignancy.

Results: The mean value for age was 43.5 years [standard deviation $(S D)=14.0$ ); duration of neck swelling was 5.9 months $(\mathrm{SD}=6.7)$; and weight of resected specimen was $157 \mathrm{gm}$ $(S D=161.0)$. Around $26.9 \%$ cases had thyroid malignancy $(n=188)$, about $77.13 \%$ cases had papillary thyroid carcinoma and $17.6 \%$ had follicular thyroid carcinoma. Age associates with risk for malignancy $(p<0.001)$, but duration of neck swelling $(p=0.513)$ and weight of resected specimen $(p=0.955)$ do not relate with this. With an increase of 1 year of age, the odds to have thyroid malignancy increase for $2 \%$. This is equivalent with $14.4 \%$ increase in cancer for every 5 -year increase in age.

Conclusion: Our study has found that increasing age is the only associated factor for risk of thyroid malignancy. When managing elderly patients who has clinically benign goiter, differential diagnosis of thyroid cancer need be considered as well.

Keywords: Goiter, Risk factors, Thyroid malignancy.

How to cite this article: Wong MW, Hadi IA, Musa KI. Revisiting Types and Risk Factors for Thyroid Malignancy in a State Endemic of lodine Deficiency Goiter. World J Endoc Surg 2017;9(2):51-54

\section{Source of support: Nil}

Conflict of interest: None

\footnotetext{
${ }^{1-3}$ Specialist

1,2Department of Surgery, Hospital Raja Perempuan Zainab II Kota Bharu, Kelantan, Malaysia

${ }^{3}$ Department of Community of Medicine, Universiti Sains Malaysia, Kubang Kerian, Malaysia

Corresponding Author: Imisairi A Hadi, Specialist, Department of Surgery, Hospital Raja Perempuan Zainab II, Kota Bharu Kelantan, Malaysia, Phone: +60139622777, e-mail: drimisairi@ yahoo.com
}

\section{INTRODUCTION}

The latest report of thyroid cancer incidence in Malaysia was $2015^{1}$ and estimates were 1.0 per 100,000 men and 2.9 per 100,000 women. We believe that these figures are rising like other countries around the world. ${ }^{2}$ The state of Kelantan, Malaysia reported as endemic of iodine deficiency goiter ${ }^{3-5}$ and with a high incidence of thyroid cancer as well ${ }^{1,6}$

There are many published reports on risk factors for thyroid malignancy, such as thyroid nodule, ${ }^{7,8}$ being female and age less than 40 years. ${ }^{910}$ Our country has multiethnic population and variable geographic landscape. Therefore, risk factors and types of thyroid malignancy may differ from the ones that have been reported.

In this study, we aim to describe distribution of different types of thyroid malignancy and to find the risk factors for having thyroid malignancy among patients underwent primary thyroid surgery at Hospital Raja Perempuan Zainab II, Kota Bharu, Kelantan, Malaysia.

\section{MATERIALS AND METHODS}

\section{Venue and Patients}

The study has been conducted in surgical department at Hospital Raja Perempuan Zainab II. It is the main referral center for thyroid diseases in the state of Kelantan, Malaysia. There are two surgeons specializes in thyroid surgery in this department. The patients who had primary thyroid surgery at Hospital Raja Perempuan Zainab II from June 2007 to December 2014, included in this study and patients who had re-operation for thyroid cancer excluded in this study.

\section{Data}

Epidemiological data and histopathological reports retrieved from Surgical Outpatient Clinic Registry. The operating surgeons retrospectively reviewed these records. All the diagnoses were verified and from the verified data, variables of interest abstracted. We took the latest result of surgery and removed previous results for this study.

Our study data contain these variables; the dependent variable was malignancy status of the resected thyroid 
specimen (coded as yes and no); the independent variables were: (a) Age (in years), (b) gender (coded as male vs female), (c) duration of neck lumps (in years) and (d) weight of resected thyroid specimen (in grams).

\section{Statistical Analysis}

All data were entered into Microsoft Excel Software for Windows (MS Excel) and were later exported to Stata version 11 (STATA) format for data cleaning and analyses.

We used mean SD and frequency (\%) to describe numerical and categorical data variables respectively. To estimate the unadjusted and adjusted risk for thyroid malignancy (age, gender, duration of neck lump and weight of thyroid specimen), we used logistic regression. The level of significance set at p-value of 0.05 (two sided).

\section{RESULTS}

Between June 2007 and December 2014, our hospital had performed a total of 723 thyroid surgeries. After excluding 24 incomplete entries and duplicates, 699 patients were eligible for the analysis.

Out of 699 patients, 85\% (594) were female and the remaining $15 \%$ (105) were male. The mean age was 43.5 years $(S D=14.0)$, mean duration of neck swelling was 5.9 months $(\mathrm{SD}=6.7)$ and the mean weight of resected thyroid specimen was $157 \mathrm{gm}(\mathrm{SD}=161.0)$.

Table 1 shows that 26.9\% (188) had thyroid malignancy. The commonest type of thyroid malignancy was papillary thyroid cancer $(77.13 \%)$, followed by follicular cancer $(17.6 \%)$ and others $(5.3 \%)$. The other types of

Table 1: Patients characteristics

\begin{tabular}{lll}
\hline Patient characteristics & Malignant & Not malignant \\
\hline Number of patients & 188 & 511 \\
Mean age & 47.25 & 42.12 \\
SD of age & 15.3 & 13.2 \\
Duration of goiter & & \\
$\quad$ Total months & 170 & 485 \\
Mean duration & 5.6 & 6.04 \\
SD & 6.8 & 6.7 \\
Weight of goiter & & \\
Total weight (gm) & 181 & 495 \\
Mean weight & 158.5 & 157.7 \\
SD & 189.4 & 149.5 \\
Gender & & \\
Male & & \\
$\quad$ Total $(\mathrm{n})$ & 38 & 67 \\
Mean & 20.2 & 13.1 \\
Female & 150 & 444 \\
$\quad$ Total (n) & 75.8 & 86.9 \\
$\quad$ Mean & &
\end{tabular}

SD: Standard deviation
Table 2: Crude odds ratio for thyroid malignancy

\begin{tabular}{llcll}
\hline & $\begin{array}{l}\text { Crude } \\
\text { odds } \\
\text { ratio }\end{array}$ & p-value & $\begin{array}{l}\text { Upper 95\% } \\
\text { interval }\end{array}$ & $\begin{array}{l}\text { Lower 95\% } \\
\text { confidence } \\
\text { interval }\end{array}$ \\
\hline Risk factors & 1.027 & $<0.001$ & 1.015 & 1.040 \\
Duration (months) & 0.991 & 0.513 & 0.965 & 1.018 \\
Weight (gm) & 1.000 & 0.955 & 0.999 & 1.001 \\
Male vs female & 1.680 & 0.021 & 1.080 & 2.600 \\
\hline
\end{tabular}

thyroid cancer were thyroid lymphoma (3), medullary thyroid cancer (1) and anaplastic thyroid cancer 6).

Table 2 shows the crude estimated odds ratio, significance value, and the corresponding 95\% confidence intervals for each of the predictor. Variable age is significantly related with the odds of having thyroid malignancy $(p<0.001)$. The estimated odds ratio indicates that when age increases by 1 year, the odds to have thyroid malignancy increases for $2.7 \%$. This is equivalent with $14.4 \%$ increase in the odds to have thyroid malignancy for every 5 years increase in the age; and with every 5 years increase in age, the increase in the odds range can be as low as $13 \%$ to as high as $15.9 \%$ at $95 \%$ confidence level. Sex is also significantly related with the odds of having thyroid malignancy, e.g., male patients have $68 \%$ higher crude odds for thyroid malignancy than female patients. For crude analysis, duration (months) and weight (gram) of the tumor do not significantly associate with the outcome at $\mathrm{p}$-value of 0.05 .

Table 3 shows that when age, duration of having the tumor, weight of the tumorresected (in grams) and sex analyzed together (covariates) in the logistic regression, only variable age is significantly related with the outcome (thyroid malignancy) $(\mathrm{p}<0.001)$. The adjusted odds for thyroid malignancy with each 1-year increase in age are at 3\%. The independent effect of sex has now become nonsignificant statistically; with the odds reduces from 1.680 (Table 2) to 1.33 (Table 3). Reduction of odds ratio for more than 20 is suggestive of confounding effect exerted by the other covariates in the model, possibly age. In addition, similar to the crude model in Table 2, duration of neck swelling and weight of resected specimen do not relate with odds of having thyroid cancer; p-values of 0.513 and 0.955 respectively.

Table 3: Adjusted odds, p-values and $95 \%$ confidence interval for the adjusted odds ratios for thyroid malignancy

\begin{tabular}{|c|c|c|c|c|}
\hline Risk factors & $\begin{array}{l}\text { Adjusted } \\
\text { odds ratio }\end{array}$ & $p$-value & \multicolumn{2}{|c|}{$\begin{array}{l}\text { (95\% confidence } \\
\text { interval) }\end{array}$} \\
\hline Age & 1.03 & $<0.001$ & 1.02 & 1.05 \\
\hline Duration & 0.98 & 0.144 & 0.95 & 1.01 \\
\hline Weight & 1.00 & 0.997 & 0.99 & 1.00 \\
\hline Male & 1.33 & 0.245 & 0.82 & 2.15 \\
\hline
\end{tabular}




\section{DISCUSSION}

A nationwide iodine deficiency disorder survey conducted by Malaysia's public health sector in 1996. ${ }^{4,5}$ It had identified Kelantan as one of the states endemic of iodine deficiency goiter. In 1993, Mafauzy et $\mathrm{al}^{5}$ reported the prevalence of endemic goiter in this state was $36.8 \%$. A repeat survey in 2010 revealed that Kelantan was still moderately deficient of iodine ${ }^{3}$ despite water iodination program and introduction of iodized salt. Although we do not have the latest incidence rates and we did not measure iodine levels in our patients, we believe that the incidence of iodine deficiency goiter in Kelantan remained high.

Prevalence of thyroid cancer in our center was $26.9 \%$. This is high in comparison to other main referral hospitals in other states of Malaysia. ${ }^{11,12}$ It also coincides with the reported high rate of iodine deficiency disorders in this region. These results seem to match the theory that chronic iodine deficiency leads to abnormal nodular thyroid growth and ultimately occurrence of thyroid malignancy. ${ }^{13}$ However, there had been studies from European countries ${ }^{14-16}$ that did not support this theory. They compared incidence of thyroid cancer in areas known endemic of iodine deficiency with areas of sufficient iodine and found no difference of thyroid cancer incidence between these areas. Also, iodination of salt was not associated with increase in incidence of thyroid cancer. Like global incidence of thyroid cancer, they found all areas showed steady increase rates of thyroid cancer incidence.

Like many published reports, our study show that the papillary thyroid cancer constitutes the highest type of thyroid malignancy followed by follicular thyroid cancer. Prevalence of anaplastic thyroid cancer was only $0.9 \%$. The significant risk factors for thyroid malignancy are age and sex at univariate level. On the contrary, when variables age, duration of having the tumor, weight of the resected tumor and sex analyzed together, age was found the only independent risk factor for thyroid cancer in our population.

Advancing age is acknowledged as an important risk for thyroid cancer. Belfiore et $\mathrm{al}^{17}$ reported that the risk of thyroid malignancy was three times higher in patients' ages more than 60 years and higher incidence of cancer in males. Studies in Great Britain ${ }^{18}$ and Brazil ${ }^{19}$ also found thyroid cancer incidence was higher in advancing age. In addition, micropapillary carcinoma of thyroid has been reported to be significantly higher in patients aged 50 years or older. ${ }^{20,21}$ Micropapillary thyroid cancer is a frequent incidental finding on histopathological reports of resected thyroid that was initially diagnosed as benign.

We could not demonstrate that duration of thyroid nodule is also a significant factor for thyroid carcinoma.
Duration of thyroid nodule is subjective depending on patient's perception and therefore, may cause lead-time bias. We believe that the presence of goiter may have been longer than the patient thought. Mafauzy et $\mathrm{al}^{5}$ reported prevalence of goiter was highest in the 36 to 45 years age group (33.9\%) and lowest in the elderly (above 56 years age) group ( $<30 \%)$. Age, an objective assessment is, therefore, a better variable to consider in this study.

Our study found that at univariate analysis, males have higher prevalence to thyroid cancer. But at multivariate analysis, gender is not a significant risk factor. Coincidentally, another state in Malaysia (Sarawak) known endemic of iodine deficiency goiter reported similar results that males have preponderance to having thyroid cancer. ${ }^{12}$ But, there were no reports of gender association with thyroid cancer in other states of Malaysia. ${ }^{7}$ Internationally, many published papers produced conflicting results on gender being a risk for thyroid malignancy. Rago et $\mathrm{al}^{9}$ reported that significant risk association was younger patients (age $<40$ ), males and having high levels of serum thyrotropin (TSH). Other papers have reported similar results; being male and having at least a single thyroid nodule would be at higher risk of having thyroid malignancy. ${ }^{10,22}$ However, there are also papers that provided different results to our study; Huan et $\mathrm{a}^{10}$ found no gender association with thyroid cancer; Miccoli et $\mathrm{al}^{23}$ reported that sex, age and volume of thyroid did not influence risks for malignancy.

\section{LIMITATIONS}

Limitation of our study includes: (a) The design was cross sectional which limits the temporal relationship to prove further the cause-effect relationship, (b) limited variables on the patients' database included as predictors for malignancy, e.g., TSH measurement were not included in this study and (c) the data came from hospital-based patients, hence, reduce the generalizability of our results to all the Kelantan general population. The strengths of our study include adequate sample size and all histopathological tests were confidently verified as all the tests were carried out at our single laboratory setting.

However, our study can improve further if there's bigger sample size to study the relationship between sex and risk for thyroid malignancy, as well as adding more variables in our registry.

\section{CONCLUSION}

Our study produced similar results to other papers; the commonest thyroid malignancy is papillary thyroid cancer and increasing age is associated with higher risk for thyroid malignancy. Sex shows significant relation 
with the outcome at univariate analysis but not at multivariable analysis but both duration of having tumor and the weight of the resected tumorare not important risk factors for thyroid malignancy. These results reminded us the need to have a high index of suspicion for cancer when managing elderly patients presenting with clinically benign goiter.

\section{REFERENCES}

1. Azizah Ab M, Nor Saleha IT, Noor Hashimah A, Asmah ZA, Mastulu W. Malaysian National Cancer Registry Report 2007-2011 [Internet]. National Cancer Registry 2015. pp.228.

2. Howlader N, Noone AM, Krapcho M, Garshell J, Miller D, Altekruse SF, Kosary CL, Yu M, Ruhl J, Tatalovich Z, et al (editors). SEER Cancer Statistics Review 1975-2012, National Cancer Institute. Available from: http://seer.cancer.gov/ csr/1975_2012/.

3. Selamat R, Mohamud WN, Zainuddin AA, Rahim NS, Ghaffar SA, Aris T. Iodine deficiency status and iodised salt consumption in Malaysia: findings from a national iodine deficiency disorders survey. Asia Pac J Clin Nutr 2010;19(4):578-585.

4. Institute for Medical Research annual report. Ministry of Health Malaysia: 20 (2003).

5. Mafauzy M, Wan Mohamed WB, Yasmin Anum MY, Musalmah M, Mustafa BE. The prevalence of endemic goitre in Kelantan, Malaysia. Med J Malaysia 1993 Mar;48(1):64-70.

6. Othman NH, Omar E, Naing NN. Spectrum of thyroid lesions in hospital Universiti Sains Malaysia over 11 years and a review of thyroid cancers in Malaysia. Asian Pac J of Cancer Prev 2009 Jan-Mar;10(1):87-90.

7. Sakorafas G, Stafyla V, Kolettis T, Tolumis G, Kassaras G, Peros G. Microscopic papillary thyroid cancer as an incidental finding in patients treated surgically for presumably benign thyroid disease. J Postgrad Med 2007 Jan-Mar;53(1):23-26.

8. Smith JJ, Chen X, Schneider DF, Broome JT, Sippel RS, Chen H, Solórzano CC. Cancer after thyroidectomy: a multiinstitutional experience with 1,523 patients. J Am Coll Surg 2013 Apr;216(4):571-577.

9. Rago T, Fiore E, Scutari M, Santini F, Di Coscio G, Romani R, Piaggi P, Ugolini C, Basolo F, Miccoli P, et al. Male sex, single nodularity and young age are associated with the risk of finding a papillary thyroid cancer on fine-needle aspiration cytology in a large series of patients with nodular thyroid disease. Eur J Endocrinol 2010 Apr;162(4):763-770.

10. Huan Q, Wang K, Lou F, Zhang L, Huang Q, Han Y, Sun H, Zhu L, Lin P, Song J, et al. Epidemiological characteristics of thyroid nodules and risk factors for malignant nodules: a retrospective study from 6,304 surgical cases. Chin Med J (Engl) 2014;127(12):2286-2292.
11. Htwe TT. Thyroid malignancy among goitrous thyroid lesions: a review of hospital-based studies in Malaysia and Myanmar. Singapore Med J 2012 Mar;53(3):159-163.

12. Htwe TT, Hamdi MM, Swethadri GK, Wong JO, Soe MM, Abdullah MS. Incidence of thyroid malignancy among goitrous thyroid lesions from the Sarawak General Hospital 2000-2004. Singapore Med J 2009 Jul;50(7):724-728.

13. Vitti P, Rago T, Tonacchera M, Pinchera A. Toxic multinodular goiter in the elderly. J Endocrinol Invest 2002;25(Suppl 10): 16-18.

14. Sehestedt T, Knudsen N, Perrild H, Johansen C. Iodine intake and incidence of thyroid cancer in Denmark. Clin Endocrinol (Oxf) 2006 Aug;65(2):229-233.

15. Pettersson B, Coleman MP, Ron E, Adami HO. Iodine supplementation in Sweden and regional trends in thyroid cancer incidence by histopathologic type. Int J Cancer 1996 Jan 3;65(1):13-19.

16. Haghpanah V,Soliemanpour B,Heshmat R, Mosavi-Jarrahi AR, Tavangar SM, Malekzadeh R, Larijani B. Endocrine cancer in Iran: based on cancer registry system. Indian J Cancer 2006 Apr-Jun;43(2):80-85.

17. Belfiore A, La Rosa GL, La Porta GA, Giuffrida D, Milazzo G, Lupo L, Regalbuto C, Vigneri R. . Cancer risk in patients with cold thyroid nodules: relevance of iodine intake, sex, age, and multinodularity. Am J Med 1992 Oct;93(4): 363-369.

18. McNally RJQ, Blakey K, James PW, Gomez Pozo B, Basta NO, Hale J. Increasing incidence of thyroid cancer in Great Britain, 1976-2005: age-period-cohort analysis. J Epidemiol Community Health 2010 Sep;64(Suppl 1):A31.

19. Brito A, Coeli C, Barbosa F, Caetano R, Santos M, Vaisman M. Thyroid cancer incidence in Brazil: an approach using polynomial models. J Epidemiol Community Health 2011 Aug; 65(Suppl 1): A179.

20. Do BA, Payne RJ, Bastianelli M, Mlynarek AM, Tamilia M, Hier M, Forest VI. Is age associated with risk of malignancy in thyroid cancer? Otolaryngol Head Neck Surg 2014 Nov;151(5):746-750.

21. Kakudo K, Tang W, Ito Y, Mori I, Nakamura Y, Miyauchi A. . Papillary carcinoma of the thyroid in Japan: subclassification of common type and identification of low risk group. J Clin Pathol 2004 Oct;57(10):1041-1046.

22. Boelaert K, Horacek J, Holder RL, Watkinson JC, Sheppard MC, Franklyn JA. Serum thyrotropin concentration as a novel predictor of malignancy in thyroid nodules investigated by fine-needle aspiration. J Clin Endocrinol Metab 2006 Nov;91(11):4295-4301.

23. Miccoli P, Minuto MN, Gallen D, D' Agostino J, Basolo F, Antonangeli L, Aghini - Lombardi F, Berti P. Incidental thyroid carcinoma in a large series of consecutive patients operated on for benign thyroid disease. ANZ J Surg 2006 Mar;76(3):123-126. 